\title{
The dissociative experiences taxon is related to fantasy proneness
}

\author{
Citation for published version (APA):
}

Giesbrecht, T. M., Merckelbach, H. L. G. J., \& Geraerts, E. G. (2007). The dissociative experiences taxon is related to fantasy proneness. Journal of Nervous and Mental Disease, 195(9), 769-772. https://doi.org/10.1097/NMD.0b013e318142ce55

Document status and date:

Published: 01/01/2007

DOI:

10.1097/NMD.0b013e318142ce55

Document Version:

Publisher's PDF, also known as Version of record

\section{Please check the document version of this publication:}

- A submitted manuscript is the version of the article upon submission and before peer-review. There can be important differences between the submitted version and the official published version of record.

People interested in the research are advised to contact the author for the final version of the publication, or visit the DOI to the publisher's website.

- The final author version and the galley proof are versions of the publication after peer review.

- The final published version features the final layout of the paper including the volume, issue and page numbers.

Link to publication

\footnotetext{
General rights rights.

- You may freely distribute the URL identifying the publication in the public portal. please follow below link for the End User Agreement:

www.umlib.nl/taverne-license

Take down policy

If you believe that this document breaches copyright please contact us at:

repository@maastrichtuniversity.nl

providing details and we will investigate your claim.
}

Copyright and moral rights for the publications made accessible in the public portal are retained by the authors and/or other copyright owners and it is a condition of accessing publications that users recognise and abide by the legal requirements associated with these

- Users may download and print one copy of any publication from the public portal for the purpose of private study or research.

- You may not further distribute the material or use it for any profit-making activity or commercial gain

If the publication is distributed under the terms of Article $25 \mathrm{fa}$ of the Dutch Copyright Act, indicated by the "Taverne" license above, 


\title{
The Dissociative Experiences Taxon Is Related to Fantasy Proneness
}

\author{
Timo Giesbrecht, PhD, $\dagger^{*}$ Harald Merckelbach, PhD, ${ }^{*}$ and Elke Geraerts, PhD $f^{* *}$
}

\begin{abstract}
Some authors have argued that nonpathological dissociation should be distinguished from a taxon form of pathological dissociation, which is indexed by the Dissociative Experiences Scale Taxon (DES-T). We tested to what extent DES-T scores are independent from fantasy immersion and whether DES-T scores are uniquely related to trauma self-reports. To this end, subsamples of undergraduate students $(n=930)$, healthy adults $(n=20)$, schizophrenic patients $(n=22)$, borderline personality disordered patients $(n=20)$, patients with mood disorder without psychosis $(n=19)$, and women with a history of childhood sexual abuse $(n=55)$ completed the Dissociative Experiences Scale and a measure of fantasy immersion. DES-T scores were related to absorption and fantasy immersion to a lesser extent than the original DES. However, the fact that nontrivial percentages within all groups, except for the healthy adults, were classified as taxon members casts doubts on the assumption that DES-T is a reliable index of pathological dissociation. Also, we found that the DES-T was not exclusively related to reports of childhood sexual abuse.
\end{abstract}

Key Words: Dissociative experiences scale taxon, fantasy proneness, childhood sexual abuse, nondissociative disorders.

(J Nerv Ment Dis 2007;195: 769-772)

$\mathrm{D}$ issociation is defined as "the lack of normal integration of thoughts, feelings, and experiences into the stream of consciousness and memory" (Bernstein and Putnam, 1986; p 727). Its official inclusion in the Diagnostic and Statistical Manual of Mental Disorders III (DSM III) (American Psychiatric Association, 1980) led to the development of the Dissociative Experiences Scale (DES) (Bernstein and Putnam, 1986), which now is the standard instrument to quantify the frequency of reported dissociative symptoms (van IJzendoorn and Schuengel, 1996). A computerized search in De-

*Department of Experimental Psychology, Maastricht University, The Netherlands; $†$ Department of Psychiatry, Mount Sinai School of Medicine, New York, New York; and †़Department of Psychology, Harvard University, Boston, Massachusetts.

Supported by a grant from the Netherlands Organization for Scientific Research (NWO), (446-06-010) (to T.G.).

Send reprint requests to Timo Giesbrecht, $\mathrm{PhD}$, Department of Experimental Psychology, Maastricht University, Postbus 616, 6200 MD, Maastricht, The Netherlands. E-mail: t.giesbrecht@psychology.unimaas.nl.

Copyright (C) 2007 by Lippincott Williams \& Wilkins

ISSN: 0022-3018/07/19509-0769

DOI: $10.1097 / \mathrm{NMD} .0 \mathrm{~b} 013 \mathrm{e} 318142 \mathrm{ce} 55$ cember 2006 using PsychINFO indicated that 271 studies have employed this measure, testifying to its widespread use.

To improve discrimination between benign and pathological forms of dissociation, Waller et al. (1996) developed the DES-T, which is an index that can be easily derived from the full scale DES. More specifically, the authors extracted 8 items from the DES tapping experiences like amnesia, derealization, and depersonalization rather than the less pathological features of dissociation, notably fantasy immersion. Waller et al. (1996) argued that by using a taxometric method involving these 8 items, one can determine taxon membership for a respondent, i.e., one can determine whether or not one exhibits a pathological degree of dissociation. Although Waller et al. (1996) provide psychometric evidence to support their approach, Watson (2003) reported that in his sample of undergraduates, the DES-T index was not stable over time, i.e., many individuals identified as taxon members were classified as nonmembers 2 months later. As well, Modestin and Erni (2004) found in their mixed sample of students and psychiatric patients that taxon membership did not predict the presence of a dissociative disorder.

The aims of the present study were to test 3 predictions flowing from the DES-T concept as proposed by Waller et al. (1996) and Waller and Ross (1997). First, the DES-T was developed to reduce the overinclusiveness of the DES by excluding absorption and fantasy immersion items. Thus, the DES-T should overlap with concurrent measures of absorption and fantasy immersion to a much lesser degree than the original DES. Second, the DES-T is thought to offer a means to discriminate pathological from nonpathological dissociation. At a minimum, one therefore expects higher percentages of taxon membership in clinical than in nonclinical samples. Third, as childhood trauma is thought to be a necessary antecedent of pathological dissociation (Waller et al., 1996; $p$ 317), one expects a robust connection between DES-T and self-reports of childhood sexual abuse (CSA).

\section{METHODS}

\section{Participants}

The study relied on a convenience sample including 930 undergraduate students enrolled at Maastricht University, 20 healthy adult women, 22 patients with schizophrenia, 20 patients with borderline personality disorder, 19 patients with mood disorder without psychosis, and 55 women with a history of CSA. Age and gender distributions for the subgroups are presented in Table 1. Undergraduate students 
TABLE 1. Mean Scores of the Various Subgroups on the Dissociative Experiences Scale (DES), the Absorption Subscale of the DES (DES-A), the Dissociative Experiences Scale Taxon (DES-T), the Dissociative Experiences Scale Taxon Membership Probability (DES-T taxon), and the Creative Experiences Questionnaire (CEQ)

\begin{tabular}{|c|c|c|c|c|c|c|c|c|c|}
\hline Subsamples & $\begin{array}{c}N \\
\text { (Women) }\end{array}$ & Age & DES & DES-A & DES-T & $\begin{array}{l}\text { DES-T } \\
\text { Taxon }\end{array}$ & $\begin{array}{c}\text { DES-T-50 } \\
(\%)\end{array}$ & $\begin{array}{c}\text { DES-T-90 } \\
(\%)\end{array}$ & CEQ \\
\hline Students & $930(699)$ & $19.67(3.13)$ & $18.95(11.26)$ & $29.57(15.81)$ & $11.26(10.33)$ & $0.13(0.31)$ & 13.80 & 7.40 & $7.53(3.72)$ \\
\hline Healthy adult women & $20(20)$ & $41.50(12.01)$ & $12.97(9.02)$ & $20.29(13.05)$ & $7.14(8.02)$ & $0.05(0.18)$ & 5.00 & 0.00 & $4.25(3.46)$ \\
\hline Schizophrenia & $22(4)$ & $38.95(11.50)$ & $21.52(16.49)$ & 30.03 (19.57) & $17.80(18.06)$ & $0.35(0.46)$ & 36.40 & 27.30 & $8.36(4.39)$ \\
\hline $\begin{array}{l}\text { Borderline personality } \\
\text { disorder }\end{array}$ & $20(12)$ & $38.15(8.35)$ & $31.02(15.97)$ & $44.14(20.97)$ & $21.14(16.79)$ & $0.38(0.46)$ & 40.00 & 25.00 & $11.75(5.05)$ \\
\hline Mood disorder & $19(12)$ & $47.16(10.01)$ & 17.83 (12.79) & $24.64(16.77)$ & $11.33(14.14)$ & $0.16(0.35)$ & 15.80 & 10.50 & $7.63(4.72)$ \\
\hline CSA & $55(55)$ & 43.09 (14.42) & $22.16(12.55)$ & 32.13 (14.98) & $14.68(11.60)$ & $0.27(0.40)$ & 30.90 & 12.70 & $8.18(3.59)$ \\
\hline
\end{tabular}

completed the questionnaires during mass testing sessions at the beginning of the semester. Healthy adult control women and women with a history of CSA were recruited through newspaper advertisements and participated in a directed forgetting study (Geraerts et al., 2006), during which DES and fantasy proneness scores (see below) were also obtained. Participants with a history of CSA had so-called continuous abuse memories, i.e., they said they had always remembered that they had been victims of CSA. Healthy adult control women explicitly denied that they had a history of childhood trauma. Patients with schizophrenia, borderline personality disorder, and mood disorder were recruited in a psychiatric facility for outpatient treatment to participate in a study on dissociative symptoms, fantasy proneness, and impulsivity (Merckelbach et al., 2005). During this study, their DES and fantasy proneness scores were collected. Inclusion and exclusion criteria for the respective groups are described elsewhere (Geraerts et al., 2006; Merckelbach et al., 2005). The current study was approved by the standing ethical committee of the Faculty of Psychology of Maastricht University.

\section{Measures}

\section{Dissociative Experiences Scale (DES)}

The DES (Cronbach's $\alpha=0.92$; Bernstein and Putnam, $1986)$ is a 28-item self-report scale that asks the respondent to indicate the frequency of various dissociative experiences, such as derealization, depersonalization, and psychogenic amnesia on 100-mm visual analogue scales. The anchors of the $100-\mathrm{mm}$ visual analogue scales are 0 (never) and 100 (always).

A subset of 8 DES items (item 1, 2, 14, 16, 17, 18, 20, and 23 ) is thought to tap the more forms of dissociation (e.g., absorption, fantasy, imaginative involvement). These items constitute the DES absorption subscale (DES-A) (Cronbach's $\alpha=0.81$; Carlson et al., 1991).

Another subset of 8 DES-items forms the Dissociative Experiences Scale Taxon (DES-T) (Cronbach's $\alpha=0.78$; Waller et al., 1996), which is thought to be especially sensitive to pathological dissociation. The DES-T total score can be obtained by averaging across DES items 3, 5, 7, 8, 12, 13, 22, and 27. Waller et al. (1996) have proposed a procedure to derive Bayesian taxon membership probabilities from these 8 items (Waller and Ross, 1997). These probabilities reflect the chance that individuals belong to the pathological dissociative taxon. For these taxon membership probabilities, we employed different cut-offs to create dichotomous measures of taxon-membership versus nontaxon-membership. The first cut-off was more liberal, whereas the second was more stringent. More specifically, participants with DES-T taxon probabilities above 0.50 were assigned to the DES-T-50 class and participants with a taxon probability exceeding 0.90 were assigned to the DES-T-90 class.

\section{Creative Experiences Questionnaire (CEQ)}

The CEQ (Cronbach's $\alpha=0.73$; Merckelbach et al., 2001 ) is an index of fantasy proneness, asking the respondent to state whether they agree with 25 statements concerning developmental antecedents of fantasy proneness, profound involvement in fantasy and daydreaming, and consequences of daydreaming. Merckelbach et al. (2001) reported adequate test-retest stability, internal consistency, and concurrent validity for this instrument.

\section{RESULTS}

\section{DES-T and Fantasy Immersion}

Table 1 presents mean scores for the DES, DES-A, DES-T, DES-T taxon probabilities, and CEQ for all subgroups. To examine to what extent DES-T indices are distinct from the more benign forms of dissociation (e.g., DES-A and CEQ), we calculated Pearson product-moment correlations between DES, DES-A, DES-T, DES-T taxon probability, and the CEQ. As can be seen in Table 2, the DES-T total score is related to a lesser degree to DES-A than the original (full scale) DES, with a further reduction in associative strength when looking at DES-T taxon probability. However, in all cases, the overlap between the various measures of dissociation is substantial. As to fantasy proneness, the DES-T correlated as much with the CEQ as did the original full scale DES. The DES-T taxon probability was, however, only modestly related to fantasy proneness and this correlation was significantly lower when compared with that between CEQ and the original DES (William's $t(927)=6.45, p<0.01$ ). 
TABLE 2. Pearson Product Moment Correlations Between the Dissociative Experiences Scale (DES), the Dissociative Experiences Scale Taxon (DES-T), Taxon Membership Probability (DES-T taxon), and the Creative Experiences Questionnaire (CEQ) in a Subsample of Undergraduates $(N=930)$

\begin{tabular}{lcccc}
\hline & DES & DES-A & DES-T & $\begin{array}{c}\text { DES-T } \\
\text { Taxon }\end{array}$ \\
\hline DES & - & - & - & - \\
DES-A & $0.92^{*}$ & - & - & - \\
DES-T & $0.86^{*}$ & $0.68^{*}$ & - & - \\
DES-T taxon & $0.60^{*}$ & $0.47^{*}$ & $0.76^{*}$ & - \\
CEQ & $0.45^{*}$ & $0.44^{*}$ & $0.41^{*}$ & $0.28^{*}$ \\
\hline
\end{tabular}

*Correlation is significant at the 0.01 level (2-tailed).

\section{DES-T in Clinical and Nonclinical Samples}

In all groups, except for our subsample of healthy adult women, a substantial minority was indicated as having a dissociative disorder, even when using the more stringent cut-off score of 0.90 (Table 1). For example, $25 \%$ of schizophrenic patients were identified as taxon members, but also $7.4 \%$ of the undergraduate sample. As to taxon membership determined on the basis of a stringent criterion, students did not differ from patients with mood disorders or women who reported CSA experiences $\left[\chi^{2}(3)=2.32, p>0.05\right]$. Likewise, the schizophrenic subsample did not differ from the sample of patients with borderline personality disorder in terms of taxon membership probability $\left[\chi^{2}(1)=0.30, p>0.05\right]$.

\section{DES-T and Sexual Abuse}

To examine whether DES-T indices would be more sensitive to a history of CSA, we conducted a stepwise binary logistic regression analysis (likelihood ratio). Using the DES, DES-A, DES-T total score, and DES-T taxon probabilities as possible predictors, we sought to discriminate between our control group of adult women with abuse history and the CSA group. Interestingly, only the DES-A predicted group membership significantly $[B=0.06, S E=0.02$, Wald $=7.91$, $d f=1, p<0.01]$, whereas all other variables were unable to further improve the prediction. This finding is further underpinned by the fact that the healthy control and the CSA group did not differ in taxon probability, as defined by the stringent criterion of 0.90 or higher $\left[\chi^{2}(1)=2.81, p>0.05\right]$.

\section{DISCUSSION}

Our findings can be summarized as follows. First, although the DES-T overlaps with the original full-scale DES to a lesser degree than the DES-A, the overlap is still substantial, indicating that the taxon measure taps a similar conceptual domain as the DES and the DES-A. Second, except for the healthy adult control women, substantial minorities within all subsamples were classified as taxon members. Third, CSA status was better predicted by nonpathological dissociation (DES-A) than by the DES-T.

Our finding that there is a substantial overlap between DES, DES-T, and the DES-A is consistent with a previous study (Levin and Spei, 2003). These authors did, however, fail to calculate DES-T taxon probabilities as proposed by Waller and Ross (1997). Even when following the Bayesian approach outlined by Waller and Ross (1977), we found the overlap between DES and DES-T to be substantial. Thus, one is tempted to follow Levin and Spei's (2003) and Holtgraves and Stockdale's (1997) line of argumentation claiming that the DES can best be seen as a scale measuring a single dimension. This would imply that various subscales of the DES (e.g., DES-A, DES-T) tap into this single dimension, a prediction supported by our data. On the other hand, although the DES-T was significantly related to fantasy proneness, this correlation was smaller than that between DES-A and CEQ, thereby providing partial support for Waller et al. (1996). Moreover, both pathological and nonpathological dissociation covary with general psychopathology, as measured with the General Severity Index of the Symptom Checklist-90-R (Grabe et al., 1999). Thus, the dissociation-fantasy proneness link might be mediated by general psychopathology.

As was the case in the study by Modestin and Erni (2004), we found little support for the idea that DES-T indices are useful in discriminating clinical from nonclinical groups. In fact, $7.4 \%$ of our undergraduates were classified as taxon members. It seems highly unlikely that all these individuals meet the criteria for a Dissociative Disorder. Although previous papers have criticized the false positive error rate of taxon indices in clinical groups (Leavitt, 1999; Modestin and Erni, 2004), our results suggest that this type of error is also a serious risk when applying such indices in undergraduate samples. Moreover, our prevalence rates are higher than the ones reported in other European studies, which report prevalence rates ranging from $1.9 \%$ (Spitzer et al., 2006) to $2.9 \%$ (Modestin and Erni, 2004). We can only speculate that this divergence in findings might be due to the fact that our undergraduate participants were younger than participants in the aforementioned studies. Taken together, these findings seem to imply that using the DES-T in groups with low base rates of dissociative disorders might produce a substantial amount of false-positive classifications, i.e., erroneously diagnosing individuals with a dissociative disorder.

Another important finding of the present study is that DES-T indices did not predict a (self-reported) history of sexual abuse. That is, percentages of taxon membership did not differ between women who reported CSA and those who had no such history. As well, in our binary logistic regression, the DES-A was a better predictor of a self-reported history of CSA than the DES-T. Of course, these findings are difficult to reconcile with the idea that CSA is a necessary precondition for the development of pathological dissociation (Waller et al., 1996). However, the present study did focus on CSA exclusively, whereas other childhood adversaries, such as physical and emotional neglect (Draijer and Langeland, 1999), might contribute to pathological dissociation.

Important strengths of the study include the large sample size of our undergraduate sample, as well as the strict selection and diagnostic criteria for our clinical samples (Geraerts et al., 2006; Merckelbach et al., 2005). The most important limitations of the study are the limited sizes of our clinical subsamples and the fact that in these groups, disso- 
ciative disorders were not formally assessed and consequently not excluded using the Structured Clinical Interview for DSM-IV Dissociative Disorders (Steinberg, 1994).

In sum, although some of our results favor the concept of the DES-T, notably the fact that DES-T overlaps to a lesser extent with fantasy proneness than the original full-scale DES, the majority of our other findings casts doubts on the assumptions underlying this concept. Thus, we found no evidence that DES-T is a fantasy-free index of dissociation or that DES-T indices can reliably differentiate between clinical and nonclinical groups. Neither was the DES-T a good predictor of self-reported childhood abuse. Together with the studies of Watson (2003) and Modestin and Erni (2004), our findings raise the question whether the global concept of taxon dissociation is useful. The development of more focused measures (e.g., focusing on depersonalization disorder) might provide a more promising approach to tap pathological manifestations of dissociation.

\section{REFERENCES}

American Psychiatric Association (1980) Diagnostic and Statistical Manual of Mental Disorders (3rd ed). Washington (DC): American Psychiatric Association.

Bernstein EM, Putnam FW (1986) Development, reliability and validity of a dissociation scale. J Nerv Ment Dis. 174:727-735.

Carlson EB, Putnam FW, Ross CA, Anderson G, Clark P, Torem M, Coons P, Bowman E, Chu JA, Dill D, Loewenstein RJ, Braun BG (1991) Factor analysis of the dissociative experiences scale: A multicenter study. In BG Braun, EB Carlson (Eds), Proceedings of the Eighth International Conference on Multiple Personality and Dissociative States. Chicago: Rush.

Draijer N, Langeland W (1999) Childhood trauma and perceived parental dysfunction in the etiology of dissociative symptoms in psychiatric inpatients. Am J Psychiatry. 156:379-385.

Geraerts E, Smeets E, Jelicic M, Merckelbach H, Van Heerden J (2006) Retrieval inhibition of trauma-related words in women reporting repressed or recovered memories of childhood sexual abuse. Behav Res Ther. 44:1129-1136.
Grabe HJ, Spitzer C, Freyberger HJ (1999) Relationship of dissociation to temperament and character in men and women. Am J Psychiatry. 156: $1811-1813$.

Holtgraves T, Stockdale G (1997) The assessment of dissociative experiences in a non-clinical population: Reliability, validity and factor structure of the dissociative experiences scale. Pers Individ Dif. 22:699-706.

Leavitt F (1999) Dissociative experiences scale taxon and measurement of dissociative pathology: Does the taxon add to an understanding of dissociation and its associated pathologies? J Clin Psychol Med Settings. 6:427-440.

Levin R, Spei E (2003) Relationship of purported measures of pathological and nonpathological dissociation to self-reported psychological distress and fantasy immersion. Assessment. 11:160-168.

Merckelbach H, à Campo J, Hardy S, Giesbrecht T (2005) Dissociation and fantasy proneness in psychiatric patients: A preliminary study. Compr Psychiatry. 16:181-185.

Merckelbach H, Horselenberg R, Muris P (2001) The Creative Experiences Questionnaire (CEQ): A brief self-report measure of fantasy proneness. Pers Individ Dif. 31:987-995.

Modestin J, Erni T (2004) Testing the dissociative taxon. Psychiatry Res. $126: 77-82$.

Spitzer C, Barnow S, Grabe HA, Klauer T, Stieglitz RD, Schneider W, Freyberger HJ (2006) Frequency, clincial and demographic correlates of pathological correlates of pathological dissociation in Europe. $J$ Trauma Dissociation. 7:51-62.

Steinberg M (1994) Structured clinical interview for DSM-IV dissociative disorders revised (SCID-D-R). Washington, DC: American Psychiatric Press.

van IJzendoorn MH, Schuengel C (1996) The measurement of dissociation in normal and clinical populations: Meta-analytic validation of the Dissociative Experience Scale (DES). Clin Psychol Rev. 16:365-382.

Waller NG, Putnam FW, Carlson EB (1996) Types of dissociation and dissociative types: A taxometric analysis of dissociative experiences. Psychol Methods. 1:300-321.

Waller NG, Ross CA (1997) The prevalence and biometric structure of pathological dissociation in the general population: Taxometric and behavior genetic findings. J Abnorm Psychol. 106:499-510.

Watson D (2003) Investigating the construct validity of the dissociative taxon: Stability analysis of normal and pathological dissociation. $J \mathrm{Ab}$ norm Psychol. 112:298-305. 